side chain (Cash et al., 1969; Hughes and Burley, 1970), thus preventing production of aldosterone, corticosteroids, and adrenal androgens. It has been reported, however, that it does not inhibit production of testicular androgens (Gaunt et al., 1968). Treatment must therefore be continued indefinitely and supplemented with corticosteroids and stilboestrol. Aminoglutethimide is now being tried in the treatment of metastatic cancer of the prostate (Fergusson and Robinson, unpublished data), and in every case we have observed a substantial fall in plasma testosterone before giving supplementary corticosteroid therapy.

There is ample evidence from both animal and tissue culture experiments that oestrogens directly inhibit prostatic gland function and its metabolism of testosterone (Huggins and Clark, 1940; Goodwin et al., 1961; Farnsworth, 1969; Belitsky et al., 1970). This may explain why most cases of prostatic cancer remain well controlled even when there is a small increase in plasma testosterone concentrations over six months. It would be of clinical interest to know if the small doses of stilboestrol that suppress testosterone production via the testicular-pituitary feedback mechanism are sufficient to exert the maximum effect on the malignant cells within the gland. This would seem to be particularly important in view of the risk of cardiovascular complications associated with prolonged administration of high doses of oestrogens.

We thank Mr. J. D. Fergusson, director of teaching and research at the Institute of Urology, and Dr. R. D. Bulbrook, director of the department of clinical endocrinology, Imperial Cancer Research Fund, for their helpful advice. We are indebted to the department of medical art at the Institute of Urology for the charts. One of us (M.R.G.R.) received a grant from the St. Peter's Research Trust.

\section{References}

Alder, A., et al. (1968). British Medical fournal, 1, 28.

Belitsky, P., Elhilali, M. M., and Oliver, J. A. (1970). fournal of Urology, 104,453 .

Bulbrook, R. D., Franks, L. M., and Greenwood, F. C. (1959). Acta Endocrinologica, 31, 481.

Cash, R., Petrini, M. A., and Brough, A. J. (1969). Fournal of the American Medical Association, 208, 1499.

Farnsworth, W. E. (1969). Investigative Urology, 6, 423.

Farnworth, W. E. (1970). Some Aspects of the Aetiology and Biochemistry of Prostatic Cancer, ed. K. Griffiths and G. G. Pierrepoint, p. 3. Cardiff, Alpha Omega.

Fergusson, J. D., and Phillips, D. E. H. (1962). British fournal of Urology,

Forchielli, E., et al. (1965). Acta Endocrinologica, 50, 51.

Gaunt, R., Steinetz, B. G., and Chart, T. Y. (1968). Clinical Pharmacology and Therapeutics, $9,657$.

Goodwin, D. A., Rasmussen-Taxdal, D. S., Ferreira, A. A., and Scott, W. W. (1961). Fournal of Urology, 86, 134.

Huggins, C., and Clark, P. J. (1940). Fournal of Experimental Medicine,

Hughes, S. W. M., and Burley, D. M. (1970). Postgraduate Medical fournal, 46, 409.

Kato, T., and Horton, B. (1968). Fournal of Clinical Endocrinology, 28, 1160.

Kelly, K. H., et al. (195i). Fournal of the National Cancer Institute, 11, 967.

Kent, J. R., and Acone, B. (1966). Excerpta Medica International Congress Series, No. 101, p. 31. Amsterdam, Excerpta Medica Foundation.

Saxena, B. B., and Gandy, H. M. (1970). In Symposium on In Vitro Procedures with Radio Isotopes in Clinical Medicine and Research. Vienna, International Atomic Energy Agency.

Southren, A. L., Gordon, G. G., and Tochimotos. (1968). Fournal of Clinical Endocrinology, 28, 1105.

Thomas, B. (1971). Journal of Chromatography, 56, 37.

Williams, J. P., Still, B. M., and Pugh, R. C. B. (1967). British fournal of Urology, 39, 549 .

Young, H. H., and Kent, J. R. (1968). fournal of Urology, 99, 788.

\title{
Prevention of Early Postoperative Deep Vein Thrombosis by Intermittent Compression of the Leg during Surgery
}

\author{
S. SABRI, V. C. ROBERTS, L. T. COTTON
}

British Medical fournal, 1971, 4, 394-396

\section{Summary}

A clinical trial is described in which the effect of intermittent compression of the lower limb during surgery on the incidence of early postoperative deep vein thrombosis was assessed. Deep vein thromboses were diagnosed by the 125Ifibrinogen uptake test. Peroperative intermittent compression was achieved by means of an inflatable plastic splint coupled to a pneumatic controller. By compressing only one leg of each patient, each patient acted as his own control.

With a sequential statistical analysis, 39 patients were required to pass the $5 \%$ level of significance. Eleven thrombi were detected in the control (uncompressed) legs and two occurred in the compressed legs; one of the latter was bilateral. The investigation shows that increasing the pulsatility of the venous flow in the leg is a potent prophylactic against postoperative deep vein thrombosis. Department of
Medical School, London S.E.5

S. SABRI, M.B., B.CH., PH.D., Honorary Senior Surgical Registrar/Lec-

v. C. ROBERTS, PH.D., M.I.E.E., Honorary Lecturer in Biomedical Engineering.

L. T. COTTON, M.CH., F.R.C.s., Consultant Surgeon and Director of the Department
Introduction

Passive exercise of one leg during surgery has been shown to reduce the incidence of early deep vein thrombosis in that leg compared with the other (control) leg by $77 \%$, as judged by the 125I-fibrinogen test (Sabri et al., 1971). Passive exercise was achieved by means of a motorized foot mover which produced continuous dorsal and plantar flexion of one foot at a rate of 50 cycles per minute and with an amplitude of $\pm 20^{\circ}$ about the vertical. At this rate and amplitude pedalling increases both the mean flow of blood in the femoral vein and its pulsatility. The mean flow is increased by $35 \%$, the peak flow by almost $60 \%$, and the pulsatility of the flow is increased fivefold (Roberts et al., 1971a).

The question now to be answered is which factor is the more effective in reducing deep vein thrombosis during surgery, increasing the mean flow of venous blood in the legs or increasing its pulsatility? We have found that the most effective means of increasing the pulsatility of venous blood flow is the application of a train of equispaced compressive impulses to the leg, produced by surrounding it with an inflatable plastic bag coupled to a special pneumatic regulator (Roberts et al., 1971b). By this method pulsatility is increased without a concomitant rise in the mean venous flow. Furthermore, this investigation has shown that intermittent compression of one leg does not lead to any significant change in the pattern of flow in the other leg. A clinical trial has been designed to evaluate the effect of increasing the pulsatility of 
venous flow in the legs during surgery on the incidence of deep vein thrombosis as detected by the ${ }^{125}$ I-fibrinogen test.

\section{Patients and Method}

Patients of both sexes aged 40 years or over who were undergoing surgical operations lasting more than 25 minutes were randomly selected and asked for their co-operation and written consent. Those who had clinical signs of recent thrombosis or who were having leg, thyroid, or vascular surgery were excluded. The thyroid was blocked with $100 \mathrm{mg}$ of sodium iodide given orally 24 hours before operation and continued daily for four weeks afterwards. An injection of $100 \mu \mathrm{Ci}$ of $125 \mathrm{I}-$ fibrinogen was given into an arm vein and the radioactivity was measured over the legs half an hour later. The counting equipment used was the Pitman 235 isotope localization monitor (Kakkar et al., 1970) and the legs were scanned according to the method of Flanc et al. (1968). Scanning of the legs began two hours before surgery and was repeated 10 minutes after surgery and daily for three days. A final scan was made on the sixth postoperative day. The diagnosis of venous thrombosis was made when the postoperative count of radioactivity at any site differed by at least $15 \%$ from (1) the preoperative value, (2) an adjacent measurement on the same leg, or (3) the same point on the other leg, and persisted for more than 24 hours.

Each patient provided his own control, one leg being intermittently compressed while the other was untouched, a technique which is valid in this instance because no significant flow changes in the control leg are produced by the intermittent compression of the experimental leg. The leg to be compressed was previously determined by drawing a card from a pack. This provided a random selection of the experimental and control legs and ensured similar numbers of right and left legs. The diathermy plate was attached to either leg in a completely random fashion. The leg to be compressed was placed in an inflatable, plastic, below-knee splint (Parke, Davis and Co.), which was attached to a pneumatic regulator. The splint was inflated at a rate of $8 \mathrm{~mm} \mathrm{Hg}$ per second to a maximum pressure of $40 \mathrm{~mm} \mathrm{Hg}$, at which level the compression was abruptly released (Fig. 1). Similar pulses were applied at one-minute intervals throughout the operation from immediately after the induction of anaesthesia until the

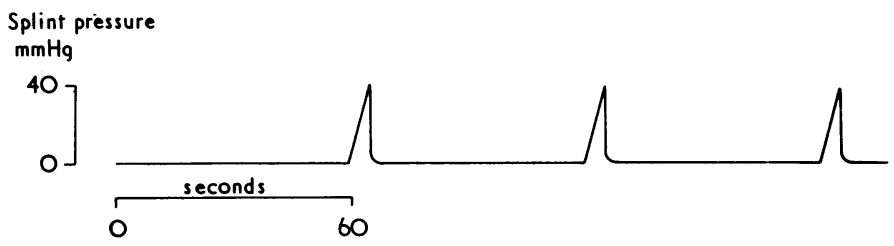

FIG. 1-Curve showing the pressure cycle used during this trial. One compression lasting five seconds and having a maximum value of 40 $\mathrm{mm} \mathrm{Hg}$ is applied to the leg once every minute throughout the operation.

application of dressings to the wound. The criteria for producing the maximal pulsatility of venous blood flow had previously been established in man and had been shown to be capable of increasing the peak venous flow by $700 \%$ and the pulsatility of the venous flow wave thirtyfold (Roberts et al., 1971b).

Statistical Design of the Trial.-The incidence of postoperative thrombosis in patients aged 40 years or more is 20-30\% (Negus et al., 1969; Kakkar et al., 1970). Thus a restricted sequential analysis was designed with $2 \alpha=0.05$, $\beta=0.05, \Theta_{1}=0.85$, which gives a probability level of $5 \%$. The trial was concluded when the sequentially plotted results crossed the chosen upper boundary. Only cases of unilateral thrombosis are used in the sequential analysis, bilateral thromboses being excluded.

\section{Results}

Thirty-nine patients were required to cross the line of $5 \%$ significance (see Fig. 2). The age of the patients ranged from 41 years to 74 years, with a mean of 54 years for those who developed thrombosis and of 59 years for those who did not, a difference which is not statistically significant. Two thromboses occurred in the intermittently compressed legs and one



FIG. 2-Sequential analysis used in this trial. The line of significance corresponds to a probability level of $5 \%$.

of these was bilateral. The incidence of thrombosis in the control legs was $28.2 \%$. The duration of operation ranged from 25 to 177 minutes and averaged 60 minutes for those who did not develop thrombosis and 85 minutes for those who did. All patients were seen subsequently by the hospital physiotherapist and had routine leg and breathing exercises.

\section{Discussion}

Intermittent compression of the legs during surgical operations seems so far to be a most effective method of preventing early postoperative deep vein thrombosis. In a similarly constructed trial, but using electrical stimulation of the calf muscles, Browse and Negus (1970) needed 110 patients to pass the $5 \%$ level of significance. In our earlier trial with a motorized foot mover (Sabri et al., 1971) 47 patients were required to reach the same level of significance. When using intermittent compression the number of patients needed to reach the $5 \%$ level of significance has been brought down to 39 .

It should be stressed that our main concern is with those thromboses that occur either during surgical operations or within $\mathbf{7 2}$ hours after them. It is these early thromboses, $80 \%$ of the total (Browse and Negus, 1970), that might be expected to be due to venous stasis and which thus might be prevented by some mechanical means during operation. There may well be other factors responsible for deep venous thrombosis which may encourage their development later in the postoperative period. We have already seen one patient who had no signs of thrombosis in his intermittently compressed leg for six days after laparotomy and yet developed clinical signs of thrombosis in both calves 10 days after operation.

We know that passive exercise during surgery increases the mean venous flow by $35 \%$ and its pulsatility fivefold (Roberts et al., 1971a). The results of using passive exercises and intermittent compression differ mainly in that whereas passive exercise increases limb perfusion, intermittent compression does not. Both methods increase the pulsatility, though the effects of intermittent compression are more pronounced. 
This would seem to indicate that pulsatile flow in the veins of the leg is a prerequisite for effective prophylaxis. However, the method by which intermittent compression prevents thrombosis is still unknown. We envisage that each compression empties the venous system of the leg, particularly the large sinuses in the soleus muscle in which thrombosis most commonly arises (Gibbs, 1957). During anaesthesia the veins of the soleus muscle seem to be functionally isolated (Clark et al., 1965). In addition, venous blood flow is markedly depressed by premedicant drugs and even more so by the induction of anaesthesia (Clark and Cotton, 1968). A low venous flow and stagnant blood in the soleal sinuses seems to favour the development of thrombosis. The effect of intermittent compression would be to alternately empty the sinuses and then to allow them to fill.

The results of our two trials of foot pedalling and intermittent compression are most encouraging. If the two series are grouped together, then in a total of 86 patients thrombosis has occurred in 24 control legs-an incidence of $27.9 \%$. Similarly thrombosis has occurred only in five legs which were either pedalled or squeezed-an incidence of only $5.8 \%$. These combined results show that there is now no doubt that reducing stasis of venous blood in the calf is a potent $(P<0.01)$ measure in the prevention of deep venous thrombosis. Further- more, the pulsatility of the femoral vein flow is a clearer reflection of the degree of venous stasis occurring in the calf than the mean level of the flow.

We are indebted to the Wates and British Heart Foundations for their generosity in financing this investigation. We would also thank Mr. H. E. Berry for kindly allowing us access to patients under his care, and Miss D. Newman for technical help.

\section{References}

Browse, N. L., and Negus, D. (1970), British Medical fournal, 3, 615. Clark, C., and Cotton, L. T. (1968). British fournal of Surgery, 55, 211. Clark, C., Cotton, L. T., and Zarek, J. M. (1965). In Biomechanics and Related Bioengineering Topics, ed. R. M. Kenedi. London, Pergamon.

Gibbs, N. M. (1957). British fournal of Surgery, 45, 209.

Flanc, C., Kakkar, V. V., and Clarke, M. B. (1968). British Journal of Surgery, 55, 742

Kakkar, V. V., Nicolaides, A. N., Renney, J. T. G., Friend, J. R., and Clarke, M. B. (1970). Lancet, 1, 540.

Negus, D., Pinto, D. J., and Brown, N. (1969). Acta chirurgica Belgica, 68, 507.

Roberts, V. C., Sabri, S., Pietroni, M. C., Gurewich, V., and Cotton, L. T. (1971a). British Medical fournal, 3, 78.

Roberts, V. C., Sabri, S., Beeley, A. H., and Cotton, L. T. (1971b).

In press. fournal, 3, 82.

\title{
Use of ${ }^{99}{ }^{9}{ }^{m}$ for the Routine Assessment of Thyroid Function
}

\author{
A. W. G. GOOLDEN, H. I. GLASS, E. D. WILLIAMS
}

British Medical Fournal, 1971, 4, 396-399

\begin{abstract}
Summary
${ }^{99} \mathrm{Tc}^{\mathrm{m}}$-pertechnetate is concentrated in the thyroid in the same way as iodide but it does not become organically bound. The uptake of ${ }^{99} \mathrm{Tcm}^{\mathrm{m}}$ is a measure of the thyroid trap, and this measurement is satisfactory as a routine test in the diagnosis of thyrotoxicosis. The reproducibility of the method is such that suppression tests can be carried out when necessary even when uptake is within the normal range of $0.4-3 \% .{ }^{99} \mathrm{Tc}^{\mathrm{m}}$ gives a low radiation dose to the thyroid and has certain other advantages over radioactive isotopes of iodine for early thyroid uptake measurements. It is particularly suitable when serial tests of thyroid function are required during treatment with an antithyroid drug.
\end{abstract}

\section{Introduction}

The measurement of thyroid uptake with radioactive iodine has been accepted as a simple and useful test of thyroid function. ${ }^{\circ}{ }^{\circ} \mathrm{Tc} \mathrm{m}$ in the form of pertechnetate is concentrated in the thyroid in the same way as iodide, and the uptake of this radioisotope can be used as an index of thyroid activity (Andros et al., 1965). It is relevant to consider therefore whether ${ }^{99} \mathrm{Tc}^{\mathrm{m}}$ is likely to have any advantages over the various radioactive isotopes of iodine which are currently available.

Hammersmith Hospital, London W12 OHS

A. W. G. GOOLDEN, M.B., D.M.R.T., Consultant Radiotherapist H. I. GLASS, PH.D., F.INST.P., Head, Radioisotope Unit E. D. WILlIAMS, M.sC., Physicist, Radioisotope Unit
Recent work has suggested that it is possible to predict which patients are likely to obtain a remission with antithyroid drug therapy by carrying out tests of thyroid function during treatment. About $50 \%$ of patients given carbimazole and L-triiodothyronine (T-3) showed suppression of thyroid uptake within three to six months of starting treatment (Alexander et. al., 1966, 1967). Suppression in these patients was tested by measuring thyroid uptake 20 minutes after an intravenous dose of ${ }^{132} \mathrm{I}$. The likelihood of remission was found to be high in patients whose thyroid uptake was suppressed under these circumstances.

When serial tests of thyroid function are required during treatment it is advantageous to use a test that measures the ability of the thyroid to trap or concentrate iodide, because this function is not directly affected by drugs such as carbimazole which act at a later stage in thyroid hormone biosynthesis. ${ }^{9} \mathrm{Tc}^{\mathrm{m}}$, which is concentrated in the thyroid but does not become organically bound, is very suitable for this purpose. We originally developed a method for measuring ${ }^{99} \mathrm{~T} \mathrm{c}^{\mathrm{m}}$ uptake in order to follow the progress of patients being treated with an antithyroid drug. Experience, however, has shown that it is a simple and reliable test of thyroid function and we now use it routinely in place of an early radioiodine uptake measurement.

\section{Methods and Patients}

Measurement of Uptake of ${ }^{99} T c^{m}$ by Thyroid.-The uptake of ${ }^{99} \mathrm{Tc}^{\mathrm{m}}$ was determined by a method which is based on the use of scanning equipment and which is described in greater detail elsewhere (Williams et al., 1971). The dose of ${ }^{90} \mathrm{Tcm}^{\mathrm{m}}(0.5 \mathrm{mCi})$ was measured with the detectors of a dual head scanner and was then given intravenously. A scan was started 20 minutes later. The number of dots per unit area in two regions immediately above and below the thyroid region was determined, 